\title{
Expectations when you are expecting in times of COVID-19
}

\author{
Debora M. Miranda, ${ }^{1}$ iD Zilma S.N. Reis, ${ }^{2}$ iD Marco A. Romano-Silva, ${ }^{3,4}$ iD Leandro Malloy-Diniz, ${ }^{4}$ iD \\ Antônio Geraldo da Silva ${ }^{5}$ iD \\ ${ }^{1}$ Departamento de Pediatria, Faculdade de Medicina, Universidade Federal de Minas Gerais (UFMG), Belo Horizonte, MG, Brazil. \\ ${ }^{2}$ Departamento de Ginecologia e Obstetrícia, Faculdade de Medicina, UFMG, Belo Horizonte, MG, Brazil. ${ }^{3}$ Centro de Tecnologia em Medicina \\ Molecular, Faculdade de Medicina, UFMG, Belo Horizonte, MG, Brazil. ${ }^{4}$ Departamento de Saúde Mental, Faculdade de Medicina, UFMG, Belo \\ Horizonte, MG, Brazil. ${ }^{5}$ Associação Brasileira de Psiquiatria.
}

Yearly, there are an estimated 213 million pregnancies worldwide. ${ }^{1}$ The coronavirus disease 2019 (COVID-19) pandemic, an unprecedented event, has affected millions worldwide and made pregnancy an international public health concern. The consequences of SARS-CoV-2 infection in pregnant women, particularly those with clinical comorbidities, are unknown. Additional concerns include the impact of reduced availability of obstetric and prenatal care during the pandemic; changes in routine and implementation of homeschooling for children; instability promoted by economic risk; and the potential direct effects of the virus on the baby. All these uncertain and fearful scenarios, isolated or combined, might have a cumulative impact as stressors on pregnant women.

A pandemic is considered a disaster, and it is well established that, in the first months following a disaster, almost half of survivors develop psychiatric symptoms. ${ }^{2}$ Among pregnant women, some special groups appear to be more vulnerable to mental disorders. Teenage pregnancy, domestic violence, and economic or educational disadvantage have been associated with a higher risk of developing psychiatric disorders.

Pregnant women might manifest depression, anxiety or posttraumatic stress symptoms, and suicidal ideation. ${ }^{2,3}$ Fatigue, sadness, fear of not being a good mother or of harming the baby, difficulty concentrating, and loss of pleasure in life are warning symptoms of which health professionals must be watchful. ${ }^{4}$ Healthcare providers should be aware and able to identify symptoms and give support to these women in the first year after giving birth. The use of a culturally appropriate mental health screening tool, such as the Edinburgh Postnatal Depression Scale, should be useful to improve access to proper treatment. After delivery, pediatricians and general practitioners are the health care professionals most often in contact with children and mothers; thus, they should be prepared for early identification and referral to treatment. Observation of the relationship between mother and child can provide insight into maternal mental health status. Infants may also show signs helpful in identifying mothers with mental health disorders, such as insufficient weight gain, irritability, and fussiness.

In societies where new mothers receive welcome visits and/or rely on community postpartum support, the pandemic might have disrupted this support network due to sanitary and social distancing concerns. Keeping usual routines or creating new ones, including socializing via digital media, are useful for providing comfort. Ensuring communication between health services, women, and their relatives is critical to managing urgent complaints such as severe anxiety or depression by referring to mental healthcare facilities. Telehealth has shown to be feasible in this setting and, although unable to replace inperson encounters, virtual platforms can be responsibly used to offer trustful advice and effective surveillance. ${ }^{5}$ Some countries have opened 24-hour mental health services for online counseling. The pandemic catalyzed the use of online services for contact with family and peers, as well as to reach psychologic and medical support, but the effectiveness of the latter remains to be shown.

Early psychosocial, educational, psychological, and pharmacological treatment should be introduced as necessary to decrease the prevalence of depression and anxiety, and the burden of these disorders on families and children. The treatment target should be to minimize maternal depressive symptoms, support family functioning, improve the mother-child relationship, and decrease incidence rates of psychiatric disorders. These measures could result in improved child development and decrease the potential for long-term consequences of the COVID19 pandemic.
Correspondence: Debora M. Miranda, Laboratório de Medicina Molecular, Faculdade de Medicina, Universidade Federal de Minas Gerais, Av. Alfredo Balena, 190, sala 114, Centro, CEP 30130-100, Belo Horizonte, MG, Brazil.

E-mail: debora.m.miranda @gmail.com

Submitted Jun 04 2020, accepted Jul 31 2020, Epub Sep 282020.
How to cite this article: Miranda DM, Reis ZSN, Romano-Silva MA, Malloy-Diniz L, da Silva AG. Expectations when you are expecting in times of COVID-19. Braz J Psychiatry. 2021;43:347-348. http://dx. doi.org/10.1590/1516-4446-2020-1209 


\section{Disclosure}

The authors report no conflicts of interest.

\section{References}

1 Sedgh G, Singh S, Hussain R. Intended and unintended pregnancies worldwide in 2012 and recent trends. Stud Fam Plann. 2014;45:301-14.

2 North CS, Nixon SJ, Shariat S, Mallonee S, McMillen JC, Spitznagel EL, et al. Psychiatric disorders among survivors of the Oklahoma City bombing. JAMA. 1999;282:755-62.
3 Poon LC, Yang H, Kapur A, Melamed N, Dao B, Divakar H, et al. Global interim guidance on coronavirus disease 2019 (COVID-19) during pregnancy and puerperium from FIGO and allied partners: information for healthcare professionals. Int $\mathrm{J}$ Gynaecol Obstet. 2020;149:273-86.

4 Stein A, Pearson RM, Goodman SH, Rapa E, Rahman A, McCallum $M$, et al. Effects of perinatal mental disorders on the fetus and child. Lancet. 2014;384:1800-19.

5 Aziz A, Zork N, Aubey JJ, Baptiste CD, D'Alton ME, Emeruwa UN, et al. Telehealth for high-risk pregnancies in the setting of the COVID19 pandemic. Am J Perinatol. 2020;37:800-8. 